\title{
A AULA: ESBOÇO DE UMA AUTO-ANÁLISE ${ }^{1}$
}

\author{
THE LESSON: AN OUTLINE OF SELF-ANALYSIS
}

Alexandre Virgínio²

\section{RESUMO}

O presente trabalho objetiva destacar a reflexão crítica como parte do processo de formação docente. Para tanto, valemo-nos de experiência vivida em sala de aula na Faculdade de Ciências da Educação da Universidade de Santiago de Compostela - Galícia/Espanha. No exercício de pensar a prática educativa lançamos mão de um caminho teórico-metodológico de caráter qualitativo. Nestes termos, e reconhecendo as propriedades e contribuições da interação e indiferenciação entre sujeito e objeto, fundamentamos nossa análise, teórica e metodologicamente, na hermenêutica de profundidade. Em essência, procuramos demarcar, a partir das interações e diálogos próprios ao contexto da sala de aula, pertinências e inadequações da e na conduta docente, quando não discente, sobretudo em termos éticos, metodológicos e conceituais. 0 resultado de nossas interpretações, ou mesmo a construção do abstrato pensado, foi colocar em relevo o papel da reflexão na formação do educador e/ou, por decorrência, na dessemelhança construída pelo diálogo entre a prática do saber (teoria) e o saber tácito (prática).

Palavras-chave: Reflexão. Hermenêutica. Interpretação. Doxa. Prática docente.

1 Este é o nome conferido por Pierre Bourdieu ao seu derradeiro escrito, 'Esquisse pour une auto-analyse', que, no Brasil, foi lançado sob o título 'Esboço de uma auto-análise', publicado pela editora Cia. Das Letras em 2005. Nesta obra, Bourdieu realiza uma auto-reflexão sem deixar-se cair em uma autobiografia. Pelo contrário, o autor procura fazer, não sem receios, uma auto-descrição sociológica colocando-se como sujeito e objeto da observação e da análise. Em nosso caso, tanto quanto Bourdieu, transitaremos pela tênue fronteira entre a auto-reflexão, o auto-equívoco e/ou nossa ignorância.

2 Doutor em Sociologia/UFRGS; Mestre em Sociologia/UFRGS; Especialista em História do Brasil/FAPA; Licenciado em História/FAPA; Licenciado e bacharel em Ciências Sociais/UFRGS. Atualmente, é professor do Instituto Federal de Educação, Ciência e Tecnologia (Ex-Escola Técnica da UFRGS). Tem experiência na área de Sociologia, com ênfase em Sociologia da Educação, atuando principalmente nos seguintes temas: classes populares, participação, democracia, emancipação e sociedade. Alem disso, é colaborador externo do Grupo de Investigação de Pedagogia Social e Educação Ambiental da Faculdade de Ciências da Educação da Universidade de Santiago de Compostela - Galícia/Espanha e da Ong Povoacão: Educação Cidadã. E-mail para contato: alexvirginio@uol.com.br 


\begin{abstract}
This paper aims to highlight the critical reflection as part of teacher training. To this end, we make use of experience in the classroom at the Faculty of Education at the University of Santiago de Compostela-Galicia/ Spain. In the exercise of thinking about educational practice we used a theoretical-methodological approach of qualitative character. Accordingly, and recognizing the contributions of the properties and interaction and differentiation between subject and object, we base our analysis, theoretical and methodological hermeneutics of depth. In essence, we demarcate, from the interactions and dialogues themselves to the context of the classroom, and inadequacies of the pertinency and teaching behavior, if not students, especially in terms of ethics, methodological and conceptual. The result of our interpretations, or even the construction of abstract thought, was to draw attention to the role of reflection in teacher education and/or, by consequence, the dissimilarity constructed through dialogue between the practical knowledge (theory) and tacit knowledge (practice).
\end{abstract}

Key Words: Reflection. Hermeneutics. Interpretation.Doxa. Teaching practice.

Por ser ciência o fator primordial da inovação, sua relevância histórica está principalmente em ser a maneira mais competente de intervenção. Assim, a prática não se esgota em ser mera aplicação, ou exercício, ou ensaio, ou efeito-demonstração, mas é parte inerente, integrante, constituinte do questionamento sistemático crítico e criativo (DEMO, 2004, p. 27).

\title{
1. PRIMEIRAS PALAVRAS
}

Estes escritos nascem do desafio de poder pensar e agir como professor reflexivo. Neste sentido, exercitaremos nossa capacidade de análise a partir de uma experiência de classe vivenciada por nós mesmos. Portanto, esta é uma reflexão que atende a uma necessidade tanto teórica quanto prática, porquanto praxiológica. Ademais, a realidade em causa formulou-se de um conteúdo que nos desafiou a descrever o que transcorreu com a perspectiva de, mais do que avaliar, verificar em que medida a prática docente cotidiana pode repercutir na formação do professorado ou mesmo em qualificação dos processos de aprendizagem e formação humana.

\section{JUSTIFICATIVA}

A motivação para o que cogitamos realizar tem origem em nossa percepção e/ou na forma como apreendemos e/ou significamos o diálogo que estabelecemos com sujeitos reunidos em torno do desafio de aprender. Para além de interpretações distintas, a oportunidade de 'fazer aula' com uma turma de alunos de pedagogia colocou-nos diante de temas, de situações de diálogo, de confronto de ideias, donde nossa participação e envolvimento, em nosso juízo, assumiu uma conotação, por vezes, superficial. Render atenção ao nosso 'que fazer' docente, mais do que servir como momento de avaliação, pode resultar na compreensão do papel da reflexão crítica da práxis político-pedagógica, seja ela nossa, seja, quiçá, daqueles e daquelas que a assumem como predicado inerente à docência.

Por outra parte, mesmo que não muito distante, os processos de interação na e da vida cotidiana, inclusive nas instituições, pode ser um bom objeto de análise das propriedades do 
diálogo em seu potencial transformador e, em nosso caso, sobretudo auto-transformador. Como apenso temos também a intenção, a partir do que Thompson (1995) chamou de 'princípio da auto-refexão', de poder identificar os possíveis obstáculos práticos à transformação interpretativa da $\operatorname{doxa}^{3}$, sobremaneira aquela presente na argumentação dos alunos.

\section{METODOLOGIA}

Nosso intento é dar consecução a um exercício de alienação no sentido conferido por Elias (1998), qual seja, de um movimento de distanciamento da realidade de modo a melhor poder observá-la e compreendê-la. Este empreendimento atende, portanto, ao desafio de evitar, através de um certo distanciamento no tempo, do desprendimento de nossos interesses, de nossas tramas afetivas ou de nossas crenças, aquilo que poderia contaminar, com juízos de valor, a interpretação e análise da realidade.

De forma correlata, atende também aos pressupostos da pesquisa-participante que se distancia do observador puro e do conhecimento absoluto na medida mesma em que sujeito e objeto constituem-se em um só, numa práxis dialógica onde o observador remete o que the é exterior a sua subjetividade que, por sua vez, condiciona aquela pela mensagem emitida por sua realidade interior. Em consequência, ainda que reconhecendo que não era nossa intenção inicial, pretende lograr êxito na tarefa de realizar um estudo auto-diagnóstico e auto-investigativo de um fragmento da realidade social da qual fomos protagonistas (GABARRÓN \& LANDA, 2006).

Em suma, trata-se de uma tentativa de articular investigação, explicação e interpretação, ou ainda, de uma oportunidade de auto-aprendizagem que toma como ponto de referência fragmentos de um diálogo intercultural em sua tentativa de estabelecer uma intercompreensão crítica (THIOLLENT, 2006). Em consequência, teremos como âncora teórico-metodológica desta empresa o que nos aporta a Hermenêutica de profundidade. Esperamos que seus pressupostos possam servir para uma melhor compreensão do alcance de nossos argumentos. Nossa expectativa é de que o enfoque interpretativo possa aclarar alguns aspectos acerca dos pressupostos de nossa compreensão cotidiana, sobretudo de nossos interesses, necessidades ou capacidades, questões que abrangem educandos e educador. Em suma, trata-se de cultivar a possibilidade de despensar ${ }^{4}$ o pensado, momento este que se configura em outra forma de pensar.

\footnotetext{
3 Expressão que deve ser percebida como um conjunto de princípios, de crenças comuns e compartilhadas aceita por todos após um processo de reconhecimento e legitimação social. Doxa são as representações dominantes, isto é, o conjunto das opiniões comuns, crenças estabelecidas, ideias preconcebidas, o que é obvio e não é discutido, que só podem se impor no conjunto de um grupo social ou no conjunto da sociedade depois de um processo de condicionamento, cuja eficácia depende de dois fatores: a racionalização e a linguagem, fundamento que nomeia a realidade e/ou o mundo de uma forma peculiar e específica (BONNEWITZ, 2003). Ou ainda, na linguagem de Bourdieu, a dóxica teria lugar (...) quando as estruturas objetivas com as quais se defronta coincidem com aquelas das quais ele é produto, o habitus se adianta às exigências objetivas do campo. Eis o fundamento da forma mais freqüente e mais oculta de censura, qual seja a de colocar em posições com direito à palavra agentes dotados de disposições expressivas de antemão "censuradas" por coincidirem com as exigências inscritas na posição (BOURDIEU, 1996, p. 72).

${ }^{4}$ Este 'despensar' pode ser apreendido como o processo de metamorfose do ego, isto é, na exploração das dimensões imaginativas em sua relação com a metamorfose do mundo, implicando aqui suas possibilidades. Este diálogo do sujeito com o mundo é tão mais próximo da ideia de compreensão quanto mais o primeiro consegue, por distanciamento, objetivação e subjetivação, desvendar, descobrir e revelar o segundo (RICOEUR, 1977).
}

Século XXI, UFSM, Santa Maria, v. 1, n. 2, p. 42-61, jul./dez. 2011 


\subsection{Hermenêutica de profundidade.}

O campo de estudos sociais demanda, sobretudo em relação as suas formas simbólicas, o desafio de sua compreensão e interpretação. Em realidade, os sujeitos na dinâmica da vida cotidiana interpretam e formulam compreensões sobre o que seja a realidade em suas várias dimensões e relações. Deste modo, vão construindo pré-interpretações ou o que Bourdieu, Chamboredon e Passeron (1987) chamariam de pré-noções e cujo resultado seria produto do que Paulo Freire (1996) nominou de curiosidade ingênua. Por assim dizer poder-se-ia sustentar que o ponto de partida da hermenêutica de profundidade é a vida cotidiana (CARIDE \& MEIRA, 1996). No caso em juízo buscaremos compreender a pertinência de nossas interpretações quando confrontadas com as interpretações dos alunos e das alunas - a doxa - em um determinado contexto, aqui circunscrito ao episódio de nossa aula. Esta doxa, entrementes, é por vezes expressão de um contexto sócio-histórico que, como tal, não pode ser desconsiderado por ocasião do que aqui pretendemos desenvolver.

Entretanto não podemos olvidar que a hermenêutica de profundidade é um processo interpretativo complexo e que apresenta dimensões analíticas distintas, porquanto principais. Dentre elas destacam-se a análise sócio-histórica, cujo objetivo é a reconstrução das condições sociais e históricas de produção, circulação e recepção das formas simbólicas; a análise formal ou discursiva, responsável por considerar o conteúdo organizativo e conceitual, quando não estrutural, dos discursos e; a interpretação/re-interpretação, que são ressignificações da doxa a partir de sua interpretação que é, sempre, uma re-interpretação e que, como tal, pode provocar transformações na interpretação dos significados, portanto da doxa (THOMPSON, 2005). Estas dimensões não são sequenciais, mas antes esferas de apreciação. Malgrado os limites de nosso objeto e de nosso intento, estaremos privilegiando a dimensão da interpretação/re-interpretação, mesmo que possamos, em boa medida, transitar pelo que sugerem as primeiras.

Nestes termos, pensamos que recuperar o contexto sócio-histórico pode contribuir para esclarecer sobre as regras e recursos disponíveis aos quais os atores se reportam ao elaborarem suas interpretações. A situação espaço-temporal específica da sala de aula demarca um campo de interação próprio de onde emergem conhecimentos e estratégias próprias à vida cotidiana de uma instituição universitária. Tais interações expressam, frequentemente, simetrias ou diferenças com o que a estrutura social aporta como recursos e possibilidades de interpretação e realização. Estas possibilidades estão presentes, além do mais, na utilização dos meios técnicos utilizados para a construção e transmissão de mensagens.

Destarte, a análise formal-discursiva, nomeadamente pelo que pode aportar a apreciação das instâncias de comunicação, das formas de organização da conversação, da estrutura de uma narração e da crítica argumentativa, concorre para que possamos apreender a maior ou menor pertinência, que é sempre contextual, dos discursos. Na mesma medida, e como ponto nodal da hermenêutica de profundidade, a reinterpretação da interpretação cumpre a função de oferecer uma explicação interpretativa da interpretação que os sujeitos sustentam do que está representado, do que é dito ou mesmo do que existe. Esta 'interpretação da interpretação' visa a oferecer às interpretações outros possíveis significados que, dependendo da coerência e profundidade de seus argumentos, e uma vez diferindo e divergindo daquela, estabelece um conflito que converge para sua transformação. Este processo foi assim sumariado por Thompson (1995, p 406-407): 
Ao receber as mensagens, as pessoas se apóiam em, e empregam convenções de vários tipos, que as possibilitam decodificar e tornar compreensivas as mensagens, aceitá-las ou rejeitá-las, tomar posição diante delas, etc. Ao procurar analisar o significado das mensagens, da maneira como são recebidas e interpretadas, estamos tentando, entre outras coisas, reconstruir o sentido que esses receptores dão às mensagens que recebem, tornar explícitas as convenções implicitamente usadas na decodificação das mensagens, e examinar as atitudes que eles tomam, explícita ou implicitamente, diante dessas mensagens. [...] podemos relacionar o entendimento quotidiano das mensagens às características sócio-históricas dos contextos de recepção, e procurar verificar se esse entendimento quotidiano se diferencia sistematicamente em relação às características sócio-históricas - por exemplo, em relação ao conteúdo de classe, conteúdo étnico, de sexo ou de idade, dos receptores. Desse modo, nós podemos assumir e analisar a intuição hermenêutica de que 'o sentido da mensagem' não é uma propriedade fixa da mensagem em si, mas é uma característica que está sendo constantemente renovada e transformada no processo mesmo de apropriação.

Nesta perspectiva, conforme sustenta Thompson (1995), podemos considerar que o conteúdo do diálogo é invariavelmente reelaborado e estendido de uma forma centrífuga e reversiva para e a partir de outros contextos de recepção e transformação, incorporando e construindo outros significados. Esta perspectiva evoca-nos, ademais, os processos de assimilação e de acomodação descritos por Piaget (1983). Em outras palavras, é um processo contínuo de interpretação, incorporação, auto-entendimento, auto-reflexão, autocompreensão e autoformação, visto que, seja ativa ou passivamente, estamos constantemente partilhando mensagens com os outros. Estes, por seu lado, em maior ou menor medida, carregam em si um potencial crítico.

A propriedade transformadora da hermenêutica de profundidade reside, portanto, na confrontação, não impositiva, da interpretação de profundidade e o entendimento cotidiano, ou seja, na divergência potencial entre argumentos cuja evidência, pertinência, plausibilidade e fundamentação da primeira intervêm na interpretação e compreensão formulada pelo segundo. Reconhecendo que a transformação interpretativa não é exclusividade deste educador e analista, portanto pode ser objeto de sujeitos mais ou menos 'leigos', propomo-nos a verificar a profundidade de nossa interpretação, sobretudo em suas dimensões ética, metodológica e conceitual como grandezas capazes de estimular o processo de auto-reflexão crítica por parte dos alunos, potenciais analistas.

\section{O CONTEXTO}

Como contexto empírico de nossas interpretações apresentamos, tão somente, o tempo pretérito de planejamento e a experiência concreta que envolveu a docência de duas aulas. As mesmas tiveram como docente o autor destas linhas e alunos e alunas do curso de Pedagogia da Faculdade de Ciências da Educação da Universidade de Santiago de Compostela. Na oportunidade atendemos a uma solicitação do professor titular da turma que, amiúde, partilhava o trânsito pelo currículo da disciplina de Pedagogia Social com outra professora. 
Nosso desafio era apresentar aos alunos e alunas, em suas primeiras classes na universidade, o pensamento de Paulo Freire. Em um primeiro momento havia a ideia de projetar um vídeo deste autor por ocasião de uma palestra em Barcelona/Espanha. No entanto, em conversa com os professores da turma, propusemos outra programação. Nossa intenção era não somente discutir a trajetória ou os fundamentos da pedagogia freiriana. Queríamos, sim, conectar as temáticas e conceitos que permeiam o pensamento do autor da 'Pedagogia do Oprimido' com a metodologia que, em cumplicidade com os alunos e com as alunas, assumiríamos como caminho. Uma vez percorrido, este caminho deveria concorrer para uma primeira aproximação com algumas categorias basilares no pensamento daquele autor: círculo de cultura, diálogo, liberdade, participação ativa, conscientização, ação, ética, justiça, democracia e cidadania.

O perfil dos alunos, por sua parte, não dista muito do que encontramos em países desenvolvidos. Em sua grande maioria o grupo era formado por jovens cuja idade não ultrapassava os 20 anos, ainda que reconheçamos a presença de pessoas com mais idade e/ou experiência. Mesmo que de forma inexata, podemos sustentar que o número de mulheres em muito superava o de homens. A área da educação segue sendo ainda um campo de atuação preferencialmente feminino, tendo que conviver, amiúde, com o desconsolo de ver os postos de chefia, malgrado variações em cada nível de ensino, sendo majoritariamente açambarcados pelos varões.

O espaço físico que partilhamos nesta oportunidade era amplo, porém não espaçoso. Explico. Apesar de a sala de aula acolher estudantes e professores com dimensões generosas, as mesmas apresentam certos obstáculos à circulação dos alunos, quando não à organização das aulas. As cadeiras e as classes, que são contíguas, estão fixadas ao chão da sala. Poucas são as cadeiras individuais, porquanto móveis, na sala. Assim, os alunos, além de terem que se acomodar com certa dificuldade - distribuídos lateralmente em grupos de quatro -, são condicionados a uma disposição organizacional que congrega, implicitamente, um certo modelo de didática, um certo padrão pedagógico e epistemológico de construção de conhecimento e/ou de relação alunos-professor. Não obstante, há uma mesa e uma cadeira à disposição dos docentes, dispostas por sobre um estrado, de onde cada professora ou cada professor pode, dependendo de sua escolha, constituir o diálogo em suas aulas. Dialogo este que pode ganhar em diversidade a partir da maior ou menor utilização das novas tecnologias a disposição do corpo docente, notadamente computador, data-show e internet. Quanto mais não seja, tal disposição e organização da e na sala de aula obedece a uma perspectiva que atravessa a maior parte do ciclo básico da educação escolar.

De posse destas informações básicas podemos, agora, adentrar no percurso de nossa aula. Na medida em que esta análise emergiu como objetivo a posteriori, tivemos muita dificuldade em capturar seus pormenores. Por consequência procedemos, tanto quanto fomos capazes, à exposição de alguns elementos que, em nosso juízo, vieram a se configurar no fluxo da mesma. Com efeito, e longe de qualquer linearidade, estaremos tão somente pontuando alguns aspectos responsáveis pelo que consideramos como o núcleo por onde estiveram, de alguma forma, canalizadas, ora mais, ora menos, as atenções, intenções, interesses e reflexões dos sujeitos. Por implicação, tomamos como relevante a consecução da aula no que concerne à interação comunicacional, porquanto argumentativa e/ou narrativa, que permeou as interações entre alunos e alunas e entre ambos e este professor. Outrossim, reconhecemos que os processos de comunicação de interação humana são muito mais ricos e complexos do que tão somente a manifestação verbal do mesmo. Permeiam nossas mensagens gestos vários, expressões faciais por vezes indecifráveis, silêncios intrigantes, olhares relutantes ou inquietos, em suma, reações inusitadas, outras imperceptíveis (BOHM, 2005). Tendo esta advertência em mente, vejamos então como transcorreu a dinâmica das e nas aulas. 


\subsection{Primeira aula}

Após sermos apresentados à turma pela professora titular da disciplina, começamos agradecendo a oportunidade e estabelecendo alguns acordos. Primeiro, que pudéssemos fazer de nossas diferenças culturais, mormente de nossa matriz linguística, mais um motivo para nos aproximar do que uma razão para movimentos de abdução. Na sequência, concentramo-nos em torno da ideia de que a qualidade do que fosse construído, naquele espaço e tempo, era responsabilidade coletiva, portanto de todos e de todas. Estabelecidas e consensuadas estas bases, inclusive em torno da metodologia das aulas, buscamos ajustar o computador para a reprodução de um pequeno videoclipe do grupo Pink Floyd em sua versão para a música "Another brick in the Wall", sem antes deixar de compartilhar informações sobre os materiais à disposição dos alunos na plataforma digital da disciplina.

Os alunos e as alunas, como comumente costumam postar-se, apreciaram com muito interesse o desenrolar do videoclipe. Imediatamente à sua conclusão, solicitamos aos estudantes que se dispusessem em círculo, arranjo este sugerido para favorecer nosso diálogo. Uma grande parte dos alunos ficou como que espantados e/ou não entendendo bem o que propúnhamos. Após alguns momentos de dúvida e entreolhares, os mesmos vieram a se acomodar no que poderíamos nominar, considerando o layout da sala, como sendo a caricatura de um círculo.

O passo seguinte foi questionar aos estudantes como haviam interpretado o que haviam assistido naquele pretérito imediato. Após um silêncio, que demorou a ser rompido, algumas falas ganharam vida. Na medida em que avançamos no tempo, estas passaram a se entrelaçar, em movimentos não contínuos e com conteúdos e significados diversos, porquanto antagônicos. $\mathrm{Na}$ medida em que estivemos com nossa percepção direcionada à apreensão da substância das mensagens, nossas anotações sobre as mesmas foram escassas. A ausência de um diário de campo, como sabemos (STÉPHANE \& WEBER, 2007), pode deixar no esquecimento muitas propriedades da realidade. Todavia, ainda que correndo o risco de ser inefetivo, acreditamos que podemos remediar o fato com uma tradução possível das principais falas e diálogos sobrevindos. Podemos sustentar que os pensamentos ganharam história nas falas, mesmo que tangíveis, dos atores em aula. Por certo que a participação deste professor, e dos alunos e das alunas, não possa ser abreviada em suas falas, serão elas nosso principal objeto de exploração. Tais falas estão antecipadas pela letra " $A$ ", quando se referirem a intervenções do corpo discente, porquanto desprovida de qualquer identificação singular, e pela letra " $\mathrm{P}$ ", quando for argumento docente.

Rompendo o silêncio inicial, seguiu-se o diálogo:

A - O vídeo mostrou uma época em que o professor falava e era ouvido, um tempo em que ele conseguia transmitir conhecimento. Muita coisa, ainda hoje, segue o mesmo;

A - Professor tem que transmitir conhecimento;

$P$ - Vejam, o conhecimento não é de fora para dentro mas, pelo contrário, é de dentro para fora. Se lembrarmos aquela brincadeira de infância chamada 'telefone sem fio' vamos perceber isto de forma mais concreta. Ou seja, ao emitirmos uma mensagem a uma primeira pessoa de um grupo e pedirmos que a mesma a transmita a outra imediatamente ao seu lado e esta a que está a seguir, e assim sucessivamente, perceberemos que ao final a mensagem inicial apresentou uma organização sintática e um significado semântico diferente daquele original;

A - O professor sabe mais que o aluno;

A - Hoje o professor perdeu a autoridade; 
P-Bem, a Espanha, como o Brasil, viveram períodos históricos com características semelhantes. Aqui vocês tiveram uma ditadura por quase quarenta anos. No Brasil experimentamos um período de ditadura, como também a América Latina, que perdurou por mais de vinte anos. Então, me parece que vivíamos um pouco a falta de liberdade na relação da sociedade com o Estado e, no âmbito da vida privada, também. Poucas vezes podíamos questionar o que os arautos do Estado ou nossos pais diziam ou faziam. O que ocorre é que saímos de uma sociedade autoritária e de um Estado autoritário e caímos em algo como 'é proibido proibir', isto é, perdeu-se um pouco a dimensão das coisas. O desafio que está colocado então é não ser, nem autoritário, mas ter autoridade, nem licencioso, mas garantir a liberdade, como afirmava Paulo Freire. Seria algo como nos disse Leonardo Boff, encontrar a 'justa medida';

Breve silêncio...

A - O que o vídeo demonstrou foi a 'produção em massa' na educação, conformando mentes. A escola cumpre a função de produção de alunos dóceis, resignados e consumistas;

A - Os professores vem aqui, colocam o power-point, explicam e não querem saber;

A - Não adianta nada, nunca vai mudar;

$P$ - Bem, penso que sempre pode haver uma saída. O ser humano é um projeto infinito. Por exemplo, certa vez um grupo de alunos no Brasil veio falar comigo ao final da aula queixando-se de um professor e perguntando-me o que eles podiam fazer para alterar a situação que, segundo eles, estava insustentável. Primeiro, disse que não queria saber o nome do professor. Depois ponderei com eles que sempre há, em qualquer aula, algo de que possamos tirar proveito, nem que a mesma sirva tão somente para despertar ou aguçar nosso senso crítico. Aliás, lembrando das aulas, todas as metodologias são válidas. O que talvez não seja muito produtivo é a hipostasia de uma mesma metodologia. Na sequência disse para os alunos que talvez fosse melhor verificar o que havia de positivo na aula do professor e comentar com ele. Depois, conforme transcorresse o diálogo poder-se-ia, quem sabe, colocar para o professor, a partir desta proximidade construída pelo elogio sincero, uma crítica em relação a outros aspectos de sua aula. Muitas vezes temos que saber compatibilizar nosso interesse imediato - que parecia neste exemplo que era solicitar a troca do professor - com nosso objetivo final - que, imaginamos, seria partilhar uma aula mais produtiva, senão agradável (Lembrei agora de Paulo Freire. Ele nutria uma crença e uma esperança muito grande no ser humano...).

A - A mídia exerce um peso grande no modo de pensar das pessoas;

A - O peso da mídia não é bem assim. $O$ indivíduo pode apagar a televisão. É uma questão de escolha;

$P$ - Bem, mas temos que considerar que o acesso ao conhecimento potencializa a capacidade das pessoas de realizarem suas escolhas. Uma coisa é uma pessoa com nível superior de ensino fazer sua escolha num momento eleitoral, por exemplo. Outra coisa é um analfabeto, cuja capacidade de discernimento sequestrada ao seu 'direito de ser mais' que a educação oferece, inflaciona o condicionamento do meio à sua capacidade de escolha;

A - A escola privada é melhor que a escola pública;

A - O problema hoje é que não se educa mais em casa. A escola tem que dar conta do conhecimento e a família, dos valores;

A - Na verdade, respeito todos tem que ter com todos;

$P$ - Nesta questão eu perguntaria para vocês: Se a família não educa em valores, como entendemos que seria sua função, o que temos que fazer? Quem educa a sociedade? Penso que temos que procurar educar a família inteira. Por isto que temos que considerar o mundo como uma imensa escola. O fato é que nós não acreditamos que uma escola pretenda fazer educação apenas com as crianças. Ou ela trabalha junto com as famílias ou estaremos construindo uma 
educação truncada e incompleta. O que imaginamos ter construído como relação social com os alunos pode ser desfeito na família, dependendo dos valores e das formas de interação que se pratica em seu íntimo.

Não havendo mais tempo para o diálogo, despedimo-nos dos alunos e das alunas dizendo que no dia seguinte poderíamos continuar nosso diálogo.

\subsection{Segunda aula.}

Para nossa segunda aula tomamos a decisão de alterarmos o que havíamos pensado inicialmente, bem como acordado com os alunos. Na medida em que percebemos que não avançamos muito no conhecimento daquelas categorias que entendíamos centrais ao pensamento de Paulo Freire, resolvemos, arbitrariamente, começar a aula apresentando Paulo Freire aos alunos. Desta forma, após comunicarmos aos alunos o câmbio que fizemos, passamos a narrar alguns episódios da biografia do autor. Perguntamos aos alunos se estava bem assim, o que eles de pronto concordaram.

Passamos então a erigir o que poderíamos considerar como o âmago da trajetória de vida do 'plantador de sonhos', tal como Moacir Gadotti se refere a Paulo Freire. De forma quase telegráfica destacamos um pouco de sua vida em família e de sua infância relativamente difícil; sua passagem pelo SESI (Serviço Social da Indústria) e pelo governo federal no início da década de sessenta do século passado, quando dirigiu o projeto de alfabetização no Ministério da Educação/Brasil; as circunstâncias do golpe militar e sua prisão; o período de exílio, na Bolívia e no Chile, destacando a escrita da 'Pedagogia do Oprimido' neste último país e sua primeira publicação em inglês, nos Estados Unidos; o período em que teve 'pouso' em Genebra, de 1970 a 1980, ponto de partida para fazer conferências por várias partes do mundo; seu regresso ao Brasil e participação na fundação do 'Partido dos Trabalhadores' em 1980; sua atuação, ao final da década de 80 e início dos anos 90, como secretário municipal de educação da cidade de São Paulo, onde implementou o projeto interdisciplinar baseado, sobretudo, em suas ideias em mais de quatrocentas escolas de um total de quase setecentas e; colocamos destaque em algumas de suas obras, como também alguns autores que o influenciaram, notadamente Karl Marx e Martin Buber.

Após esta breve historieta da vida de Paulo Freire, e com o objetivo de incitar os alunos ao debate e à reflexão sobre a realidade brasileira, porquanto latino-americana, projetamos um pequeno vídeo de animação cujo título era 'Reflexo'. Seu conteúdo refere-se à trajetória de uma criança que, no trajeto de sua infância, tem que conviver com contextos de violência e de indiferença social, algumas das faces da exclusão social a qual o mesmo se vê condicionado. Entrementes e em nosso juízo, este vídeo também sugere que o acesso a bens de consumo, senão materiais, depende do acesso ao mundo dos livros, por suposto, do conhecimento. No entanto, a promoção a este mundo, neste vídeo, é constantemente obstaculizada. Quando tudo parece estar perdido e de quem menos se esperava ajuda à criança, daquele que mais interditava àquela o direito ao saber, eis que lhe oferece um livro. Tal fato sugere que nem tudo está perdido, que vivermos em um mundo com justiça segue sendo uma viva esperança.

Imediatamente solicitamos aos alunos suas impressões sobre o mesmo. Com uma falha de memória irremediável lembramos tão somente do comentário de um aluno. Segundo este, o fato de que justamente o policial, que no vídeo constantemente está a reprimir a criança, venha a ajudá-la no final é muito irônico, senão uma anedota. Para este aluno a figura do policial está associada à repressão. De partida concordamos com esta perspectiva. Em princípio não são poucos 
os casos de policiais no Brasil envolvidos com grupo de extermínio ou com milícias urbanas ilegais. Todavia, asseveramos que este fato poderia, a partir do pensamento de Paulo Freire, ser apreendido como a manifestação da própria esperança, esperança de que mudar é possível, de uma profunda crença na potencialidade do ser humano, em sua infinita capacidade de 'ser mais', de poder ser o que ainda não se é.

Antes de terminarmos esta segunda aula, e na medida em que estávamos acuados pela falta de tempo, propusemos uma avaliação da qualidade de nossa aula. Solicitamos aos alunos que falassem como haviam percebido e/ou sentido o tempo que passamos em diálogo. Desafiamos os estudantes para que manifestassem o que haviam gostado, o que pensavam ter sido proveitoso. Um aluno pôs-se a falar ponderando que a aula trazia consigo a oportunidade de refletir e de expressar o que se estava a pensar. Outro aluno, de modo distinto, fez-nos uma crítica. Para ele talvez não fosse necessário gastar muito tempo na exposição da biografia de Paulo Freire e mais, talvez, na apresentação de suas ideias ou mesmo dos autores que o influenciou. De pronto concordamos e acolhemos esta crítica. Sustentamos, ademais, que nossa escolha deveria ser vista dentro do dilema de que, ao optarmos por conhecer algo, implícito à nossa eleição está o fato de que deixaremos ainda um mundo na ignorância, ainda por conhecer.

Na medida em que o tempo nos foi implacável, tivemos que passar à conclusão de nosso encontro. Entregamos para os alunos e para as alunas um pequeno apanhado que escrevemos sobre as ideias de Paulo Freire. Por derradeiro, lembramos de dois livros que eles talvez pudessem dar uma atenção. Um deles seria o de Bourdieu e Passeron, 'A reprodução'. O outro, do escritor russo Máximo Gorki, cujo título é 'A mãe'.

\section{DIMENSÕES DE ANÁLISE}

Não desconhecemos que a realidade empírica acima desenhada não passa de algo muito limitado ou mesmo que representa, tão somente, vestígios de um contexto muito mais denso e emaranhado. Porém, e não querendo emascular nosso intento inicial, propomo-nos a realizar uma breve, e por certo relutante, análise destes 'momentos de aula'. Procuraremos desenvolver nossa crítica em torno de três dimensões, quais sejam: a dimensão metodológica, a dimensão ética e a dimensão dos conceitos. Em nossa ad-mira-ação adotaremos como balizadores os pressupostos teórico-metodológicos da hermenêutica de profundidade, acima apresentados, não sem reconhecer que tais desígnios sejam passíveis de melhores e mais profundas contribuições.

\subsection{Dimensão Metodológica}

O teor concernente a esta grandeza pode ser enfocado a partir de sua correspondência com uma percepção mais acurada do contexto sócio-histórico. Este aspecto poderia explicar a dificuldade dos alunos em participarem mais ativamente da aula, porquanto os momentos de silêncio. Em realidade, ao propormos uma aula dialogada foi como se convidássemos os alunos a banharem-se no mar em um dia frio de inverno. A crônica de seu contexto é resultado de uma expectativa de comportamento, senão de papeis sociais, que permeia os ritos da tradição.

Tanto a disposição do mobiliário, que em nada difere do que imaginávamos peças de museu pedagógico ${ }^{5}$, quanto o habitus ${ }^{6}$ dominante, encerram um modo de atuação do qual, dos

\footnotetext{
5 Em Santiago de Compostela há um museu pedagógico onde se pode apreciar peças e/ou elementos que constituíam o universo da sala de aula, sobretudo do século XIX e primeira metade do século XX.

6 Por habitus, assevera Bourdieu, deve-se considerá-lo como um conjunto ou [...] sistemas de disposições duráveis, estruturas estruturadas predispostas a funcionar como estruturas estruturantes, isto é, como princípio gerador e estruturador das práticas e das representações que podem ser objetivamente 'reguladas' e 'regulares' sem ser o produto da obediência a regras, objetivamente adaptadas a seu fim sem supor a intenção consciente dos fins e
} 
educandos, não se espera mais do que escutar e transcrever os saberes que lhes são apresentados como dignos de serem aprendidos. Em agravo, a sociedade espanhola viveu, durante mais de uma geração, a imposição dos limites à liberdade, cujo conteúdo não nos sentimos seguros, neste momento, de definir sua conotação: a ditadura franquista. Some-se a isto a influência da Igreja Católica, com seus cânones seculares, e um sistema de ensino cuja organização é o resultado de imperativos legais que, a despeito de sua ciclotimia e dos benefícios de que sejam portadores, não são o resultado de aspirações democráticas devidamente manifestas e reconhecidas.

Portanto, não nos parece imponderável distinguir que a atuação docente tenha, de modo geral, uma imagem situada na aula expositiva, no discurso vertical e unidirecional, em um certo grau de invariabilidade metodológica e de uma posição de poder instituída e instituinte. Isto poderia explicar, amiúde, o diálogo não manifesto que muitos alunos mantiveram conosco, sobremaneira com nossos argumentos e/ou forma de proceder em aula, ou ainda, a razoável hesitação que boa parte dos alunos demonstraram quando convidados a constituírem um círculo. Os entreolhares podem significar a esperança de obter, naquelas pessoas que estão acostumados a conviver, alguma segurança quanto ao modo como deveriam proceder diante de uma situação pouco comum. De resto, como não há uma cultura de um diálogo ativo mais constante, seria de se esperar uma certa dificuldade na externalização dos argumentos discentes.

Diante destes rasgos contextuais pensamos que talvez fosse melhor a assumpção de outros recursos de comunicação, de modo que nos desse a conhecer, em maior amplitude e profundidade, os argumentos dos alunos. Com efeito, outras possibilidades metodológicas poderiam merecer melhor atenção. Não somente o trabalho em pequenos grupos poderia ser uma perspectiva possível, como também uma maior exploração da pedagogia da pergunta não seria em nada anódina. A nossa dificuldade em apresentar questões que pudessem desaguar em outras perspectivas de interpretação, por parte dos alunos, pode ser justificada, mas não desculpada, por nosso limitado conhecimento e vivência da vida cotidiana daqueles. É de se supor que dar à consciência maiores ferramentas acerca do que os discentes conhecem, vivenciam ou significam, a partir de sua cultura, poderia ser premissa para uma melhor problematização de suas interpretações.

Outro fator contextual que entendemos importante considerar é o tempo de diálogo. Muitas interpretações, a julgar pelo número de pessoas que participaram da aula, ficaram no mundo do desconhecido porque o tempo necessário para sua emergência não foi satisfatório. A disposição para a externalização do pensamento pressupõe estar-se suficientemente motivado e desafiado a fazê-lo. Na medida em que estamos tratando de diálogo entre seres humanos, temos que considerar que os mesmos são resultado, cada qual, de uma conformação identitária decorrente de processos singulares de objetivação e subjetivação, amiúde represente modos de vida por vezes tão particulares, quanto são resultado de interações sócio-históricas distintas. Portanto, os sujeitos formulam suas escolhas e ações a partir de uma capacidade diferenciada de apreensão das oportunidades objetivas, tanto quanto não possuem as mesmas condições para fazê-lo (BOURDIEU, 2001).

Nesta perspectiva, o que resulta de motivação necessária à participação ativa em um diálogo é algo sempre indeterminado. Por conseguinte, e se se quer lograr êxito no desafio de

o domínio expresso das operações necessárias para atingi-los e coletivamente orquestradas, sem ser o produto da ação organizadora de um regente (BOURDIEU, 1983, p. 60-61). A expressão sistema de disposições é o que melhor designa, segundo Bourdieu (1983), o conceito de habitus como produto de uma ação organizadora que confere sentido aos condicionantes esternos, estruturais, como também manifestação de uma maneira de ser, um estado habitual, quando não uma predisposição e inclinação a ser. 
favorecer aqueles que dialogam o conhecimento das múltiplas interpretações possíveis, haveria de diversificar as formas de diálogo. Isto posto, não vemos como poderia isto ser oportunizado considerando o tempo que dispúnhamos para a consecução da aula. Além de restringir as possibilidades de motivação à participação ativa no diálogo, a escassez de tempo também pode interferir na própria percepção do tempo. Por um lado, na medida em que não se sentem sujeitos produtores do tempo, acabam por vivenciar um desajustamento entre suas expectativas em relação à aula e às condições objetivas da mesma. Tal estranhamento pode confluir para que determinados alunos percebam o tempo da aula como um 'tempo morto', um tempo presente que 'não passa'. Por outro lado, este 'tempo vazio' é vivido como uma certa ansiedade visto que representa a perda da autonomia e da segurança do habitus hegemônico face a uma situação geradora de incertezas.

Aqui podemos identificar e explicar uma certa dificuldade dos alunos de vislumbrarem uma relação com o futuro de modo diverso, como algo resultado de um potencial de liberdade que ainda não está desenvolvido e que poderia significar a aproximação do mundo das oportunidades do mundo das probabilidades (BOURDIEU, 2001). Inversamente e por ironia, a sublimação do habitus conformado à educação bancária pode resultar na mesma percepção de um tempo 'sem sentido'. O que muda aqui é que, neste prisma, o que aumenta é a angústia de ver seu potencial de liberdade reprimido. No limite, o sentimento de insegurança relacionado ao mundo objetivo, do que se passa em classe, é substituído pela aflição provocada pela distância entre o mundo das oportunidades e o mundo das possibilidades. Esta discussão em torno da questão do tempo é somente um exemplo de um conjunto de temas que podem emergir a partir do diálogo em aula e que, se não for bem equacionada a relação entre tempo e conteúdo do diálogo, corre-se o risco de 'perder-se tempo' e de se ter um diálogo superficial, avesso ao que seria substancial.

\subsection{Dimensão Ética}

O termo ética apresenta uma variedade de interpretações. Em realidade, é uma expressão polissêmica. Para efeito de nossa análise estaremos considerando as assertivas que apresenta Fernando Savater (2003) sobre o tema. Neste sentido, uma conduta ética respeita ao conjunto de princípios, valores e saberes que mobilizamos por ocasião da tomada de decisões. Tais pressupostos estão fundamentados naquilo que respeita a dignidade humana, a solidariedade, a inviolabilidade da pessoa humana, a liberdade de construir, numa base comum de significados, relações com os outros onde nossos juízos apresentam-se estreitamente ligados ao respeito à diferença e onde podemos confrontar nossas ideias morais democraticamente. Isto pressupõe não julgar jamais o outro pelo que é ou por suas crenças, senão por seus argumentos e atitudes, confrontando-se com o outro em torno do diálogo sobre a escolha que melhor simetria apresente com aqueles pressupostos, quando não da materialização da cidadania. Esta, aliás, depende muito do direito irrenunciável a que todos têm que acionar quando da participação em sua construção, a qual depende, amiúde, do contexto de direitos de cidadania que a sociedade oferece ao indivíduo, sobretudo o direito ao conhecimento.

A partir desta concepção de ética tomamos como nodal deste domínio a crítica a alguns de nossos argumentos e/ou atitudes nas aulas referidas. Com uma mirada mais acurada e com uma prática reflexiva menos próxima à consciência prática, poderíamos ter evitado que argumentos e exemplos fossem apresentados sem um mínimo de observação quanto ao sentido e conotação que poderiam suscitar. Senão, vejamos. Os argumentos que utilizamos para confrontar a perspectiva determinista e fatalista que um ou outro aluno, uma ou outra aluna, se aventuravam 
a externalizar, não apresentaram consistência lógica, em nosso ponto de vista, capaz de provocar uma re-interpretação por parte dos educandos.

O que se fez foi, com um exemplo ancorado em uma experiência pessoal, tentar mostrar que se deve buscar caminhos ainda impensados que possam desaguar na alteração de dada realidade ou mesmo das pessoas. Ao aludir a nossa experiência pessoal, resultado de nossa falta de ponderação, transitamos com muito perigo por perto de um comportamento pouco digno de cumprimento, para não dizer antiético. A 'lição' que oferecemos envolvia uma interpretação da aula de um outro professor. Mesmo que tenhamos feito o alerta quanto ao anonimato deste professor, penso que tais exemplos podem levar alguns alunos ou alunas a apreenderem esta situação como fragilidade de caráter, pessoal e profissional. Em outras palavras, tal exemplo pode suscitar interpretações de nossa conduta em relação a nossos pares, interpretações essas permeadas por valores que distam do conteúdo da cidadania, qual sejam, falsidade e hipocrisia. A probabilidade de lograr êxito teria sido melhor caso tivéssemos sequestrado à história, inclusive espanhola, processos sociais que melhor testemunham o fato de que a vida humana é um campo dinâmico e aberto ao mundo das possibilidades.

Por outras palavras, esta nova consciência já vem sendo construída nos interstícios da atual sociedade, seja a partir dos movimentos de resistência ao impacto sócio-ambiental do sistema capitalista, seja pelo desenvolvimento de alternativas às alternativas de desenvolvimento. A 'emergência' destas possibilidades obedece à premissa de que, como nos lembrava Paulo Freire, o amanhã não está posto. Assim, de acordo com Santos (2006), existem campos sociais onde é possível frutificar, senão alargar, o diálogo democrático entre diferentes formas de conhecimento, as experiências de trabalho, produção e de consumo solidários, como também, de reconhecimento social, de radicalização democrática e de produção diversificada da informação.

Estes são saberes e experiências cuja objetividade concorre para corroer as formas de dominação e exploração, desde a natureza, passando pelo racismo, sexismo, ou mesmo xenofobia. Ademais, não são poucos os exemplos destas 'emergências'. O diálogo entre a biotecnologia e os grupos indígenas e a tensão entre o agronegócio e a agricultura sustentável são alguns dos conflitos gerados por esta outra racionalidade que, dentre outras coisas, não aceita a fatalidade, o determinismo e, pelo contrário, sustenta o desafio de manter-se inconclusa a partir da certeza, em um mundo de incertezas, de que a realidade sócio-ambiental pode ser sujeito e objeto de uma gama imensa de possibilidades. A função do pensamento aqui é pensar o "ainda não', de modo de o mesmo venha a parir ações que desemboquem em uma outra realidade (SANTOS, 1996; 2006; ESTEBAN, 2009).

A expectativa de que esta visão possa alargar sua potência na realidade demanda que a educação e a formação humana venham a ser efetivas no sentido de oportunizar, sobretudo nos sistemas de ensino, em cada pessoa, em cada sujeito, o exercício do pensar, de duvidar do que é pensado e do que se pensa do que é pensado e vivido. O que estamos sustentando é que esta que pretende ser uma racionalidade alternativa deve constituir correspondência na construção das relações sociais, em especial nos processos de aprendizagem e de formação humana.

\subsection{Dimensão Conceitual}

O caso em tela revela o diálogo entre o fragmento de duas culturas. Por óbvio que a cultura do povo espanhol é muito mais diversa do que o modo de vida galego. Por certo também 
que a cultura galega é muito mais variada do que pode representar a sombra de um carvalho ${ }^{7}$, a pimenta sobre o polvo ${ }^{8}$ ou a forma de elaborar o orujo ${ }^{9}$. De outra parte, não podemos sustentar que comer churrasco, tomar chimarrão ou falar português sintetiza o fato de ser brasileiro. Somos portadores de uma infinidade de formas de lidar com nossa tensão com a natureza, bem como de transcender o mundo com atos de reflexão em nosso processo constante de humanização (BRANDÃO, 1985). Chamar a atenção sobre nossas particularidades culturais, porquanto próprias, serve para demarcar a dificuldade que enfrentamos muitas vezes quando nos propomos a construir, senão uma cultura multi-referenciada, ao menos uma perspectiva cosmopolita ${ }^{10}$. Esta tarefa demanda um certo esforço no sentido de construção de determinados consensos e, em se tratando de conhecimento científico, da compreensão de determinados conceitos.

Esses conceitos, uma vez sendo objeto de e em nossas argumentações, revelam uma maior ou menor adequação em relação à realidade que pretendem explicar, representar ou transformar. O objetivo agora é, portanto, apresentar alguns argumentos que, em função de seu grau de profundidade, conformação lógica e conexão contextual, podem concorrer para uma ressignificação da doxa. Esta está traduzida nas falas abaixo. As mesmas aparecem grifadas em itálico e receberam, em continuidade, nossas interpretações.

A. Professor tem que transmitir conhecimento: Uma das propriedades da hermenêutica é fazer ver que toda interpretação muda o que interpreta. Em realidade, como somos seres eminentemente significantes, nenhuma tradução pode ser efetivada de modo literal. Basta lembrarmos que existe sempre a obra de arte original, e como tal é valorada, e a cópia que, por ser cópia, não é igual à original. A cópia é, na verdade, outra obra, mito semelhante à sua

\footnotetext{
7 Árvore típica da Galícia.

8 Especiaria da culinária galega.

9 Aguardente elaborada a partir do sumo da uva.

${ }^{10}$ A consecução da razão cosmopolita requer a construção do que Santos (2005) chamou de 'trabalho de tradução'. Os processos de tradução é que permitiriam a conversão dos saberes científicos em saberes cotidianos, bem como alçar problemas deste último a objeto das preocupações dos primeiros (FOUREZ, 1995). Esta tradução deve poder ser pensada ainda dentro da perspectiva da ecologia dos saberes onde, a partir do intercâmbio e comunicação de saberes, busca-se a maximização da contribuição de cada saber no desafio da compreensão da realidade. Mais do que isto, a tradução deve ser percebida como um diálogo e confronto de culturas que busca, a partir de valores mínimos compartilhados, a inteligibilidade recíproca entre os saberes e experiências do mundo na perspectiva de construir uma nova concepção de emancipação social alternativa à globalização neoliberal (SANTOS, 2005). O trabalho de tradução está vinculado à preocupação de Santos em como articular e compatibilizar teoricamente toda a infinita diversidade do mundo. Sendo este de uma totalidade inesgotável não há teoria que consiga abarcá-lo. Deste modo, a tradução se apresenta como procedimento que procura tornar inteligíveis e recíprocos os saberes. Aqui as experiências, reveladoras de saberes, devem ser apreendidas em sua relação com a totalidade, tanto quanto descoladas da mesma. Noutras palavras, a superação da dominação requer não só a crítica às causas e efeitos intrínsecos como, substancialmente, o recurso a um pensamento que vise alçar à realidade o que há de original, singular, de autenticidade no dominado, para além de sua posição na relação de dominação. Com efeito, para Santos (2006) a função do trabalho de tradução não incide somente sobre um saber como processo espiral de diálogo, portanto não excludente, entre saberes relacionais e/ou inaugurais, mas como um fundamento capaz de sustentar e mobilizar para práticas sociais contrahegemônicas. É nisto, aliás, que o trabalho de tradução entre saberes configura o experimento da hermenêutica diatópica. Por esta entendamos o diálogo entre duas ou mais culturas a partir de suas premissas de argumentação - ou topoi (universo de sentidos comuns) - e a partir de um reconhecimento recíproco de suas incompletudes. Ao apresentar como horizonte a dignidade humana, a hermenêutica diatópica procura confrontar os traços culturais de socialização de uma cultura com outra. O que se busca é que ambas culturas possam alargar o máximo possível a consciência de sua incompletude, premissa para potencializar os saberes e práticas. Em termos concretos, Santos tem procurado encontrar isomorfismos entre diferentes culturas no âmbito da vida produtiva e das várias concepções de sabedoria e/ou de visões de mundo, sejam eles hegemônicos ou contra-hegemônicos. Para este autor, com o processo de tradução apresenta-se a possibilidade da promoção e/ou articulação de saberes contra-hegemônicos, premissa para a construção da globalização contra-hegemônica (SANTOS, 2006).
} 
referência, mas não igual (MATURANA \& VARELA, 2001). Inobstante, a ideia de que o professor tem que 'transmitir' conhecimento é epistemologicamente impossível de se materializar. Como seres únicos, com capacidade de conhecimento e apreensão da realidade sempre de forma própria, nossa relação com o mundo, e o conhecimento que dele somos capazes de construir, é sempre uma operação singular de interpretação. Esta capacidade está relacionada ao saber pensar, esta inclinação de, mais do que saber criticar, fazer autocrítica, duvidar do que pensa, colocar em questão o vínculo do conhecimento com o que consideramos ético e saber ver o conteúdo social, quando não ideológico, presente no campo conceitual. Em resumo, o conhecimento vem de dentro para fora e não o contrário (DEMO, 2002).

B. Professor sabe mais que o aluno: $\mathrm{O}$ que o professor domina em realidade é um conjunto de saberes, sobretudo pertinentes a um campo científico e sobre o qual ele depositou suas energias e motivações para se apropriar. Neste sentido, ele domina um conjunto de conceitos e lógicas próprias a este campo, que são alienígenas à realidade conceitual de muitos alunos e de muitas alunas. Isto posto, temos duas questões a considerar, ambas de natureza política. Uma primeira é relativa a uma relação de poder. O campo científico já não pode mais ser visto como despregado das relações de poder, ou mesmo ideológicas, que permeiam a sociedade (BOURDIEU, 1983a; DEMO, 2004; "Autor", 2006). Assim, muito das interpretações científicas, apesar de atenderem aos critérios de validade deste campo, expressam perspectivas conceituais vinculadas a interesses sociais. Um exemplo disto pode ser aludido, face à atual conjuntura global, à transferência de fundos de capitais públicos para bancos e seguradoras privadas. Sua justificativa ancora-se em argumentos emanados de especialistas do campo da economia. Aqui temos o que podemos adjetivar como o lado político e ideológico do conhecimento científico (DEMO, 2004). Quanto mais não seja, o argumento do aluno sugere que um dos atores nada sabe. Com efeito, aqui o saber é também uma relação de poder. Isto nos remete à segunda questão, qual seja, epistemológica. O conteúdo da doxa alude a um educando que não sabe. Na medida em que não sabe, no diálogo com o professor ele pouco pode contribuir pois, desde a mais tenra idade, fazem-no acreditar que ele pouco ou nada pode aportar em relação ao que deve vir a saber. Então, aquele que sabe o saber que se deve saber tem o direito de dizer a sua palavra e, ao fazêlo, interpretar o mundo à sua maneira. Ao segundo, resta aprender que a organização deste mundo corresponde a esta interpretação que lhe é exógena. Outra possível interpretação, mais próxima de uma situação em que o conhecimento científico pudesse resolver problemas concretos de sua vida (FREIRE, 1987), fica, portanto, obstaculizada à consciência. Para continuarmos no mesmo exemplo, uma vez considerado no seu direito de dizer sua palavra, pode questionar a razão do porquê conceder recursos públicos para determinados grupos econômicos e certas empresas e não utilizar os mesmos montantes na potencialização de políticas destinadas à redução da pobreza ou da desigualdade social. Em síntese, o professor aparece como sujeito, ainda que tão somente como ministrador de aulas, de copiador de cópias, sem qualquer desafio à construção do conhecimento. Do aluno, ao contrário, espera-se que se assuma o papel de simples objeto, que reproduza e/ou copie a cópia do conhecimento que se lhe está disponibilizando. Ciência, que é processo de inovação permanente, através do questionamento sistemático, crítico e criativo, passa ao largo do sistema educativo, sobremaneira na universidade (DEMO, 2004). Nos próprios termos deste autor (2004, p. 15): A aula não pode mais ser a definição do professor, mas a pesquisa, entendida como princípio educativo, ou seja, como expediente para gerar ciência e promover 0 questionamento crítico e criativo.

C. Não adianta nada, nunca vai mudar: Este argumento não leva em conta a história como processo, e sim como lei. Ela representa a ideia de que nossas expectativas não podem distar das experiências já postas em curso. Desconhece a dinâmica dialética que existe entre o 
mundo da realidade e o mundo das possibilidades. A realidade, como resultado de formas de pensar e agir que, em algum momento, eram tão somente perspectivas possíveis, passa a ganhar vida nos processos objetivos de existência, é ignorada. Incógnita também está a possibilidade de que a riqueza da experiência da humanidade, a realizada e a potencialmente realizável, possam constituir-se como recursos à disposição em nossa orientação diante do devir histórico (MANNHEIM, 1962; SANTOS, 2006). Por outro lado, revela o lado frágil da cidadania. Se por um lado a cidadania requer a garantia de direitos humanos básicos - alimentação, moradia, saúde, educação, lazer, trabalho, liberdade, produção cultural, consumo sustentável - que nos garantam um mínimo de dignidade humana, não podemos esquecer aqueles que já a desfrutam, que muito da garantia do acesso a estes direitos depende de nossa atuação participativa e democrática na polis, de modo que nossas decisões e ações concorram para a democracia radical e a cidadania plena, isto é, sua extensão a todos e todas que constituem as sociedades e de todas as formas de vida. Aliás, precisamente porque o mundo não é o que queremos que ele seja, há algo a ser feito (SAVATER, 2003). Em sentido convergente, podemos sustentar que uma das razões intrínsecas de ser da educação é a própria incompletude do ser humano. Por que somos imperfeitos e incompletos cumprimos uma vocação natural de poder 'ser mais'. Este 'ser mais' se dá em um mundo inacabado. Portanto, somos seres históricos que, através do modo como vamos sendo no mundo, vamos cambiando e cambiando este mesmo mundo. A qualidade desta mudança é que quer uma educação libertadora, porquanto cidadã. Transformação esta que busca conferir e fortalecer sua perspectiva humanizadora (PAULO FREIRE, 1987). Esta certeza é compartilhada com a conviç̧ão de que, como seres humanos, podemos vir a conhecer melhor o que já sabemos e a reduzir o espaço da ignorância a partir da capacidade de aprender sobre aquilo que não sabemos. Segundo Paulo Freire (1996), é a consciência de nossa inconclusão que funda a abertura necessária para se colocar no e a caminho para conhecer mais.

D. O peso da mídia não é bem assim, o indivíduo pode apagar a televisão. É uma questão de escolha: Esta interpretação nos remete ao pensamento de Marx ${ }^{11}$ quando sustenta que muito do que pensamos é resultado de nossa prática social. De um lado, temos uma dinâmica interior que interpreta e ressignifica os dados exteriores, a partir de suas relações com outros signos interiores. Por outro lado, o selo ideológico do contexto social por onde transitamos deixa sua marca em nosso modo de pensar e de ser. Por isso podemos dizer que nossa individualidade é social (BAKHTIN, 2006). Por outras palavras, este é o diálogo dialético entre ator e contexto, entre sujeito e estrutura, ou ainda, como diria Edgar Morin (2000), o que permite afirmar que produzimos a cultura que nos produz. É neste diálogo entre indivíduo e sociedade que temos que situar a questão chave do conhecimento. $O$ acesso ao conhecimento, porquanto de sua criação, concorre para a autonomia do sujeito na dinâmica de suas relações sociais. Em outras palavras, o conhecimento lhe confere maior margem de manobra, maior potencial de interpretação e de compreensão da realidade para além daquelas que o campo social lhe oferece. Portanto é nesta perspectiva que gostaríamos que fosse compreendida nossa interpretação: "o acesso ao conhecimento potencializa a capacidade das pessoas de realizar suas escolhas". Em suma, é o conhecimento vivificado por nossa capacidade de aprendizagem que nos permite alargar a distância e a dependência de nossos condicionantes externos. Com e através dele podemos conferir conotações outras aos contextos por onde transitamos, conotações e conexões estas para além, inclusive, da utilização técnica do conhecimento, isto é, em seu 'efeito de

\footnotetext{
${ }^{11}$ Não recordamos qual em qual passagem de sua obra ele faz esta assertiva, ou mesmo, se é uma
} ressignificação nossa de seus escritos mais gerais, sobretudo no debate com os idealistas hegelianos. 
poder' no sentido de potencializar estratégias alternativas de intervenção, quiçá de alteração das bases materiais e culturais do contexto (DEMO, 2002). Destarte, entendemos que, para aqueles aos quais lhe for negado o direito à educação, é muito menos provável que possam realizar escolhas de modo mais autônomo, fragilizados que estão em sua capacidade de interpretar e compreender as mensagens externas, mormente, da mídia.

E. A escola privada é melhor que a escola pública: Esta interpretação, com este significado, não é incomum ao que sugere no contexto espanhol, tanto quanto em relação à realidade educacional brasileira. Entrementes, gostaríamos de sustentar que as diferenças existentes entre ensino público e ensino privado são mais contextuais do que endógenas às características específicas de cada uma destas esferas educativas. Senão, vejamos. A escola privada atende, preferencialmente, um segmento da sociedade que, em não se satisfazendo com o que aporta a escola pública à educação dos alunos, busca o que seria uma educação que possa oferecer algo mais aos neófitos deste grupo. Poderíamos distinguir este grupo como um segmento social cujos membros possuem nível superior de ensino, acesso a bens materiais e culturais diversificados, elevado padrão de vida garantido pela propriedade e volume, tendencialmente elevado, de bens e de capital. A criança educada neste contexto, quando passa a frequentar o universo escolar, encontra, ademais, um currículo organizado e prescrito e cuja homologia com seu ambiente familiar e sociocultural permite uma sincronia entre o texto escolar e o contexto de sua vida. Em decorrência, a possibilidade de êxito encontra maior probabilidade, nem tanto pelo modo como está organizado o processo de ensino e mais pela congruência de seu currículo com aspectos concernentes ao modo de vida deste grupo. Inversamente, os alunos que frequentam a escola pública deparam-se, muitas vezes, com o que Boudieu chamou de histeresis do habitus. A hysteresis representa o desajuste do habitus no interior do campo, ou ainda, seu descompasso com o mesmo provocado pela inadaptação das condições objetivas nas quais foi configurado, em certo momento, com as práticas sociais reconhecidas como legítimas, e que devem ser perseguidas, no campo (BOURDIEU, 1983; BONNEWITZ, 2003). Assim, a criança que se desenvolveu em um contexto social distante e diferente da interpretação do conhecimento científico que oportuniza a escola, vai encontrar muito mais dificuldade em conferir significado aos conhecimentos escolares. Isto é tão presente para as classes populares no Brasil, porquanto para os ciganos (gitanos) e imigrantes na Espanha. Desta forma, dizer que a escola privada é de melhor qualidade do que a escola pública demandaria, em nosso juízo, considerar para sua análise os fatores internos de organização e funcionamento da mesma e, da mesma forma, o contexto cultural do qual provém os educandos, suas famílias e a comunidade local da qual fazem parte. Não obstante, haveria que discutir que critérios são utilizados para definir a qualidade da escola, critérios estes que apresentam sempre uma correspondência com uma perspectiva de formação humana, às vezes mais próxima do modo de vida de um grupo, às vezes distante dos atributos culturais de outro.

A partir desta atmosfera acreditamos que podemos sugerir, ou mesmo substantivar, o que chamamos de obstáculos à interpretação da doxa. Tendo em vista o que aludimos até aqui, podemos inferir que tais obstáculos não são exclusivos, mas tão somente o que nossa capacidade de apreensão conquistou à realidade enquanto formulação de nossa compreensão. Dentre estes destacamos aqueles concernentes à inadequação do tempo de diálogo em relação aos recursos metodológicos e ao conteúdo do diálogo; o magro domínio do contexto e do quadro conceitual sobre o qual emergem as mensagens e/ou os discursos; a utilização de argumentos que, por sua ambiguidade, e menos por sua profundidade, pode concorrer para alargar excessivamente 0 campo das interpretações; e o preconceito presente em interpretações recorrentes, senão circulares. Estes seriam entraves a uma possível re-interpretação da doxa que mereceriam, cada 
qual, um desdobramento interpretativo que, no desígnio deste espaço, não temos condições de conquistar.

\section{CONCLUSÃO}

As interpretações que fizemos até aqui não se constituíram como refratárias a qualquer crítica ou mesmo risco de fugir ao rigor metodológico. Sabemos, por um lado, que tanto o referencial teórico-metodológico, o objeto da análise e nossas interpretações poderiam ser eivados por outras contribuições. Diante disto poderíamos nos defender afirmando que não foi nossa intenção construir uma argumentação portentosa. O que fizemos no escopo em causa foi procurar refletir, teórica e metodologicamente, sobre nossa prática docente e, assim o fazendo, fazendo-a práxis.

Não obstante, reconhecemos que não exploramos o conjunto das propriedades da hermenêutica de profundidade, mas, tão somente, seu laivo principal, qual seja, como capacidade de interpretação de interpretações. Sem embargo, procuramos conferir profundidade a esta reinterpretação, de modo que assumisse um grau de adequação, bem como de fundamentadas razões, capaz de, dentro de condições de não-imposição e de não-exclusão, justificar, defender ou criticar uma interpretação em função de sua maior ou menor plausibilidade e adequação ao contexto da interpretação. Foi esta preocupação que nos guiou nas críticas e interpretações que sustentamos por ocasião da apreciação das dimensões metodológica, ética e conceitual.

Nestes termos, e no ocaso desta reflexão, mais provincial do que providencial, gostaríamos de assinalar que, além do que possa representar para o leitor, o que procuramos fazer foi ponderar sobre o alcance e a aliança que existe entre a prática teórica e a teoria em prática de um docente. O que colocamos como nosso desafio foi, a partir da análise de algumas horas de aula, colocar em relevo o potencial de transformação da prática docente a partir dos aportes conceituais e operacionais, tomados aqui menos como identificadores da doxa e mais como um processo de autoanálise capaz de modificar o sentido colocado à ação pela consciência prática.

Em sentido correlato, nossa motivação, desde o planejamento das aulas até a consecução destas linhas, foi sempre a de construir um fundo comum de conhecimento, entre nós e os alunos, entre este docente e as alunas. Além do que, mesmo que não tenhamos trabalhado com o conceito de cidadania, nos parece plausível sustentar a interpretação de que a partir da vivência de uma aula, e até mesmo de sua interpretação, podemos estar menos educando para a cidadania e mais educando, nomeadamente no ensino universitário, na cidadania.

Uma derrisória interpretação. Alguém poderia sustentar que é muito incerto supor que esta reflexão terá algum desdobramento em nossa futura práxis docente. Bem, diante disto não nos resta mais do que sustentar que esta é uma interpretação possível. Aliás, a discutibilidade é um dos principais elementos de cientificidade (DEMO, 2004). No entanto, esta seria uma interpretação não propriamente desta aula. Estaríamos já ponderando sobre uma outra interpretação. Estaríamos falando, na verdade, de uma outra aula. 


\section{REFERÊNCIAS BIBLIOGRÁFICAS}

BAKHTIN, Mikhail. Marxismo e filosofia da linguagem. São Paulo: Hucitec, 2006.

BOHM, David. Diálogo: comunicação e redes de convivência. São Paulo: Palas Athena, 2005.

BONNEWITZ, Patrice. Primeiras lições sobre a sociologia de Pierre Bourdieu. Petrópolis, RJ: Vozes, 2003.

BOURDIEU, Pierre. Esboço para uma teoria da prática. IN. ORTIZ, Renato (org.). Pierre Bourdieu: Sociologia. São Paulo: Ática, 1983. (pg. 46 - 81). $122-155)$

O campo científico. In: ORTIZ, Renato (Org.). Pierre Bourdieu: Sociologia. São Paulo: Ática, 1983a. (p.

. A economia das trocas lingüísticas: o que falar quer dizer. São Paulo: EDUSP, 1996.

Meditações Pascalianas. Rio de Janeiro: Bertrand. Brasil, 2001.

Esboço de uma auto-análise. São Paulo: Cia. das Letras, 2005.

BOURDIEU, Pierre; CHAMBOREDON, Jean-Claude \& PASSERON, Jean-Claude. El ofício del sociólogo. México: Siglo Veinteuno, 1987.

BRANDÃO, Carlos Rodrigues. A educação como cultura. São Paulo: Brasiliense, 1985.

CARIDE, José António \& MEIRA, Pablo A. O diálogo paradigmático na educación social. In: Revista Galega de Educación. n. 27, 1996, p. 16-20.

DEMO, Pedro. Complexidade e aprendizagem: a dinâmica não linear do conhecimento. São Paulo: Atlas, 2002.

Pesquisa e construção de conhecimento: metodologia científica no caminho de Habermas. Rio de Janeiro: Tempo Brasileiro, 2004.

ELIAS, Norbert. Alienação e envolvimento. Rio de Janeiro: Bertrand Brasil, 1998.

ESTEBAN, Maria Tereza. Breves notas sobre um pensamento fecundo. In: FREITAS, Ana Lúcia Souza de \& MORAES, Salete Campos de. (Orgs.). Contra o desperdício da experiência: a pedagogia do conflito revisitada. Porto Alegre: Redes, 2009. (p. 123 - 142).

FOUREZ, Gerard. A construção das ciências: introdução à filosofia e à ética das ciências. São Paulo: UNESP, 1995.

FREIRE, Paulo. Pedagogia do oprimido. Rio de Janeiro, RJ: Paz e Terra, 1987.

Pedagogia da autonomia - Saberes necessários à prática educativa. Rio de Janeiro, RJ: Paz e Terra, 1996.

GABARRÓN, Luís R. \& LANDA, Libertad Hernandez. O que é a pesquisa participante? In: BRANDÃO, Carlos Rodrigues \& STRECK, Danilo (orgs.). Pesquisa participante: a partilha do saber. Aparecida, SP: Idéias Et Letras, 2006. (p. $93-121)$.

MANNHEIM, Karl. O homem e a sociedade. Rio de Janeiro: Zahar, 1962. 
MATURANA, Humberto \& VARELA, Francisco J. A árvore do conhecimento: as bases biológicas da compreensão humana. São Paulo: Palas Athena, 2001.

MORIN, Edgar. Ciência com consciência. Rio de Janeiro: Bertrand Brasil, 2000.

PIAGET, Jean. A epistemologia genética. IN.: PIAGET, Jean. Os pensadores. 2. ed. São Paulo: Abril Cultural, 1983. (p. $127-190)$.

RICOEUR, Paul. Interpretação e ideologias. Rio de Janeiro: Francisco Alves, 1977.

SANTOS, Boaventura de Sousa. Para uma pedagogia do conflito. In: SILVA, Luis Heron da et al. (org.). Novos mapas culturais, novas perspectivas educacionais. Porto Alegre: Sulina, 1996. (pg. $15-33$ ).

O Fórum Social Mundial: Manual de uso. São Paulo: Cortez, 2005.

A gramática do tempo: para uma nova cultura política. São Paulo: Cortez, 2006.

SAVATER, Fernando. Los caminos para la libertad: Ética y educación. Madrid: Fondo de Cultura Económica de España, 2003.

STÉPHANE, Beaud \& WEBER, Florence. Guia para a pesquisa de campo: produzir e analisar dados etnográficos. Petrópolis, RJ: Vozes, 2007.

THIOLLENT, Michel. A inserção da pesquisa-ação no contexto da extensão universitária. In: BRANDÃO, Carlos Rodrigues \& STRECK, Danilo (orgs.). Pesquisa participante: a partilha do saber. Aparecida, SP: Idéias Et Letras, 2006. (p. $93-121)$.

THOMPSON, John B. Ideologia e cultura moderna - Teoria social crítica na era dos meios de comunicação de massa. Petrópolis, RJ: Vozes, 1995.

VIRGÍNIO, Alexandre. Conhecimento e sociedade: diálogos impertinentes. In: Revista Sociologias, ano 8, n. 15, jan/jun/2006. (p. 88 -137). 